\title{
Rural population survey of behavioral and demographic risk factors for loaded firearms
}

\author{
D L Nordstrom, C Zwerling, A M Stromquist, L F Burmeister, J A Merchant
}

\begin{abstract}
Objectives-In the United States, firearm deaths are almost as frequent as motor vehicle deaths. Firearm unintentional and suicide death rates are raised in rural areas. This study examines firearm prevalence and storage practices in three different types of rural households.

Methods-Adults from a stratified random sample of 983 households in a rural Iowa county were interviewed. The $\chi^{2}$ test of independence was used to assess association between loaded, unlocked firearms and seven behavioral and demographic risk factors.

Results-Nearly $67 \%$ of respondents reported firearms in their households. Nearly $7 \%$ of households had a loaded, unlocked gun. Prevalence of firearms at home was higher while prevalence of loaded, unlocked guns was lower than reported in other surveys. Prevalence of loaded, unlocked guns in farm households, $10.5 \%$, was about twice the level in town households, $5.5 \%\left(\chi^{2}\right.$ test, $\left.\mathrm{p}=0.033\right)$. Having taken a gun safety course was associated with more than double the prevalence of a loaded, unlocked gun, $13.5 \% v 5.1 \%\left(\chi^{2}\right.$ test, $\left.p=0.001\right)$. The prevalence of loaded, unlocked guns in households with a handgun, $19.3 \%$, was four and one half times higher than in households with a long gun only, $4.2 \%\left(\chi^{2}\right.$ test, $\mathrm{p}=0.001)$. Households with someone with a lifetime prevalence of alcohol abuse or dependence were about twice as likely as other households, $13.0 \% v 6.6 \%\left(\chi^{2}\right.$ test, $\mathbf{p}=0.004)$, to report having loaded, unlocked firearms.

Conclusions-Anyone interested in promoting safe storage of firearms in rural homes should consider these observations.

(Injury Prevention 2001;7:112-116)
\end{abstract}

Keywords: firearms; Iowa; rural population; alcohol abuse

Firearm discharges kill almost as many people each year in the United States as motor vehicle crashes. ${ }^{1}$ In fact, in 1993 age adjusted death rates from these two causes were identical. ${ }^{2}$ Since the end of World War II, the death rate per capita has doubled for firearm homicides and has increased by half for firearm suicides. ${ }^{3}$ The United States has a vast private inventory of firearms, ${ }^{4}$ but public opinion is divided about whether keeping a gun in the home makes it more or less safe. ${ }^{5}$
To better understand the distribution and storage of firearms in rural communities, ${ }^{6}$ we added firearm questions to a survey of health and safety in Iowa. (Although technically a firearm is a particular kind of gun, ${ }^{3}$ in this paper we use the words firearm and gun as if they were the same.) Firearm unintentional and suicide death rates are raised in rural places, ${ }^{7}$ where one quarter of Americans live. In this exploratory analysis, in addition to assessing firearm prevalence and storage patterns among farm, town, and other rural households, we examined associations between unsafe firearm storage and several potential risk factors.

\section{Methods}

STUDY POPULATION

The firearm questions were included in a larger study that has been described elsewhere. ${ }^{8}$ Briefly, we chose the study county (1990 census population, 11624 with 20.1 persons per square mile) because it has no place with 2500 or more persons (the minimum population required to be urban in the United States), no history of university studies, no significant difference from the mixed economy typical of rural counties in Iowa (including $19.3 \%$ of the labor force in agriculture), and no difference from the dominant pattern of Iowa family farms raising corn, soybeans, and hogs.

In 1993 we developed a registry of study county residents. We obtained names from motor vehicle registration, telephone directories, land ownership maps, local government, schools, direct mail companies, and others. We identified 5248 unique households in the county. Residential institutions, including three nursing homes and one residential care facility for the mentally retarded, were ineligible. Using a list of computer generated random numbers, we sent recruitment letters to 20-30 households each week until reaching our goal of enrolling 1000 households in the health and safety survey. The random sampling was stratified by residence-farm, town, and non-farm, non-town - with oversampling of farm households to better understand the role of agricultural exposures. If the inhabitants of the household were living in the countryside and actively farming, the household was a "farm" household; if they were living in one of the county's towns, the household was a "town" household; and if they were living in the countryside but not actively farming, the household was a "non-farm, non-town" household.

Of the 2496 households verified as eligible during 1994-98, $1052(42.1 \%)$ provided at least one adult who agreed to be interviewed. 
We interviewed at least one adult from 1004 $(95.4 \%)$ of these 1052 households before stopping enrollment. In addition to the $42.1 \%$ of verified, eligible households that agreed to participate, an additional $25.0 \%$ (624 of 2496) indicated they would be willing to be contacted regarding participation in round two of the larger study.

To determine if our sample was representative of the study county, we surveyed by phone 200 households chosen randomly from households that had refused to participate in the survey. Households were similar by proportion with a male-female couple $(64.4 \%$ of participants $v 63.0 \%$ of refusers, $\chi^{2}$ test, $\mathrm{p}=0.738$ ), proportion with children $(33.2 \%$ of participants $v 33.5 \%$ of refusers, $\chi^{2}$ test, $\left.\mathrm{p}=0.927\right)$, average age of male adults ( 51.6 years among participants $v 50.5$ years among refusers, $t$ test, $\mathrm{p}=0.394)$, average age of female adults $(52.3$ years among participants $v 54.3$ years among refusers, $t$ test, $\mathrm{p}=0.172$ ), and proportion that worked on a farm in the past 12 months (43.7\% of participants $v 42.0 \%$ of refusers, $\chi^{2}$ test, $\mathrm{p}=0.653)$. Households differed by proportion with a high school graduate $(92.9 \%$ of participants $v 88.5 \%$ of refusers, $\chi^{2}$ test, $\mathrm{p}=0.033)$.

\section{DATA COLLECTION}

The University of Iowa institutional review board approved the health and safety study protocol and data collection instruments. We invited all adults in enrolled households to be interviewed and obtained informed consent in writing from all participants. Because study participation meant virtually a one day commitment for the household, a $\$ 50$ cash payment was offered to participating households. Like other small parts of the survey, the topic of firearms was not mentioned to potential participants. Focusing on respiratory illness and injury, the study employed several means of data collection. These included a 60-90 minute interview and a 90 minute health screening of each adult. Interviews were conducted in English at the study's rented office in the county seat. We also did an environmental assessment of the home and property of each household, lasting 2-3 hours on farms and 60-90 minutes at other homes. Trained staff collected data from study participants during 1994-98, using Epi-Info version 5 for computer assisted personal interviewing.

Our survey included all 18 firearm questions from the Injury Control and Risk Survey (ICARIS), a nationwide telephone poll conducted by the Centers for Disease Control and Prevention in 1994. Two of us (CZ and AMS) wrote 17 additional firearm questions. The survey asked respondents whether their homes, vehicles, and other buildings on the property of the home currently had firearms, regardless of who the firearm owner was. We instructed respondents to include only working handguns, pistols, rifles, shotguns, and automatic and semiautomatic weapons. Excluded were $\mathrm{BB}$ and pellet guns, tear gas guns, and guns that can not fire, such as antiques or guns for display. If any firearm was stored loaded, the household was considered to have a loaded firearm. If any loaded firearm was stored unlocked, the household was considered to have a loaded, unlocked firearm. Our interview defined locked as requiring a key or combination to be opened. We also asked respondents, "Have you ever taken a gun safety course?"

The breadth of the health and safety survey allowed us to examine seven potential risk factors for loaded guns. We selected the male respondent from households with a male respondent and the female respondent in other households to obtain data on the number, type, and storage practice of firearms. From the answers of these same adult respondents, we determined the household level of exposure to each of four risk factors. These four included type of rural residence-farm, town, or nonfarm, non-town; age of adult; presence of children under 18 years; and presence of a handgun in the household. From the same male and female respondents whose gun information we used, we analyzed their individual history of gun safety training (see above question) for the fifth risk factor.

From the answers of all adult respondents in each household, we classified each household's exposure to alcohol abuse. We used two measures of alcohol abuse, including one screening and one quantity-frequency scale, for the sixth and seventh risk factors. In the health and safety survey, the alcohol questions preceded the firearm questions, with questions on other topics occurring between these two modules. First, we asked the four questions of the CAGE (Cut down, Annoyed, Guilty, Eye opener) questionnaire": "Have you ever felt you should cut down on your drinking? Have people ever annoyed you by criticizing your drinking? Have you ever felt bad or guilty about your drinking? Have you ever had a drink first thing in the morning to steady your nerves or to get rid of a hangover (eye opener)?" When Buchsbaum et al evaluated the CAGE instrument among medical outpatients diagnosed with alcohol abuse or dependence by Diagnostic and Statistical Manual of Mental Disorders (third edition, revised) criteria, a CAGE score of 2 or more positive responses was associated with a sensitivity of $74 \%$ and specificity of $91 \% .{ }^{10}$ We classified any household with at least one adult respondent who answered two or more of these questions affirmatively as having lifetime prevalence of alcohol abuse or dependence. Second, we asked, "On about how many days did you have five or more drinks of beer, wine or liquor on the same occasion during the past 30 days?" This question has been asked by the Centers for Disease Control and Prevention to measure current episodic heavy drinking, also called "binge drinking". Self reported alcohol use corresponds closely with alcohol consumption estimated from alcohol sales data. ${ }^{11} \mathrm{We}$ classified any household with at least one adult respondent who answered one or more days to this question as having binge drinking.

STATISTICAL METHODS

Our hypothesis-exploring, cross sectional analysis compared the prevalence of loaded, 
Table 1 Firearm ownership by type of firearm and selected household characteristics in a rural county of Iowa, 1994-98

\begin{tabular}{lllllll}
\hline Household characteristic & No & $\begin{array}{l}\text { No with firearm } \\
\%(n)\end{array}$ & p Value* & $\begin{array}{l}\text { No with 1+ } \\
\text { handguns \% (n) }\end{array}$ & $\begin{array}{l}\text { No with 1+ } \\
\text { shotguns \% (n) }\end{array}$ & $\begin{array}{l}\text { No with 1+ } \\
\text { rifles \% (n) }\end{array}$ \\
\hline $\begin{array}{l}\text { Total sample } \\
\text { Region }\end{array}$ & 983 & $66.6(655) \dagger$ & & $29.5(290)$ & $56.4(554)$ & $54.8(539)$ \\
$\quad$ Farm & & & & & & \\
$\quad$ Non-farm, non-town & 200 & $75.8(284)$ & 0.001 & $33.2(110)$ & $69.8(231)$ & $65.6(217)$ \\
$\quad \begin{array}{l}\text { Town } \\
\text { Age of adult }\end{array}$ & 452 & $61.1(276)$ & & $23.5(67)$ & $58.0(116)$ & $61.5(123)$ \\
$\quad$ 18-34 & 103 & $72.8(75)$ & 0.028 & $22.3(23)$ & $57.3(59)$ & $51.5(53)$ \\
$\quad$ 35-64 & 568 & $75.7(430)$ & & $32.7(186)$ & $60.6(344)$ & $57.0(324)$ \\
$\quad \begin{array}{l}\text { Presence of children <18 years } \\
\quad \text { Yes }\end{array}$ & 312 & $67.3(210)$ & & $26.0(81)$ & $48.4(151)$ & $51.3(160)$ \\
$\quad$ No & 292 & $79.1(231)$ & 0.004 & $29.8(87)$ & $64.4(188)$ & $54.8(160)$ \\
\hline
\end{tabular}

${ }^{*} \mathrm{p}$ Values were determined by the $\chi^{2}$ test of independence of the proportion with firearm from the level of household characteristic. †This is an estimate adjusted for the residence region stratified sampling design.

unlocked firearms at varying levels of exposure to seven household characteristics. We used the $\chi^{2}$ test of independence to assess bivariate association between the prevalence of firearms with the prevalence of exposure to rural household type, the age of adult respondent, and the presence of children under age 18 . We used the same test to assess bivariate association between the prevalence of loaded, unlocked firearms with the prevalence of exposure to these three factors and to having taken a gun safety course, the presence of a handgun, a positive CAGE screening result, and binge drinking. For each analysis, all households with nonmissing information on the outcome and exposure variables were included. For each $\chi^{2}$ test, the null hypothesis was that the proportions of households with firearms (or with loaded, unlocked firearms) among the levels of exposure were equal. To see how strongly the exposure variables are related, we determined the Spearman correlation coefficient for each pair of exposure factors. To account for oversampling farm households, we used unpublished information from the 1990 United States Census on Population and Housing on the number of farm, town, and non-farm, non-town households in the study county to calculate adjusted

Table 2 Prevalence of loaded, unlocked firearms and selected household characteristics in a rural county of Iowa, 1994-98

\begin{tabular}{|c|c|c|c|c|}
\hline Household characteristic & No & $\begin{array}{l}\text { No with } \\
\text { firearm }\end{array}$ & $\begin{array}{l}\text { Firearms loaded and } \\
\text { unlocked } \%(n)\end{array}$ & $p$ Value ${ }^{*}$ \\
\hline \multirow{2}{*}{\multicolumn{5}{|c|}{ Region }} \\
\hline & & & & \\
\hline Farm & 331 & 284 & $10.5(35)$ & \multirow[t]{3}{*}{0.033} \\
\hline Non-farm, non-town & 200 & 155 & $8.0(16)$ & \\
\hline Town & 452 & 276 & $5.5(25)$ & \\
\hline \multicolumn{5}{|l|}{ Age of adult } \\
\hline $18-34$ & 103 & 75 & $7.6(8)$ & \multirow{3}{*}{0.714} \\
\hline $35-64$ & 568 & 430 & $8.3(47)$ & \\
\hline $65+$ & 312 & 210 & $6.7(21)$ & \\
\hline \multicolumn{5}{|c|}{ Presence of children $<18$ years } \\
\hline Yes & 292 & 231 & $3.8(11)$ & \multirow[t]{2}{*}{0.002} \\
\hline No & 691 & 484 & $9.4(65)$ & \\
\hline \multicolumn{5}{|c|}{ Ever had gun safety course } \\
\hline Yes & 310 & 257 & $13.5(42)$ & \multirow[t]{2}{*}{0.001} \\
\hline No & 668 & 459 & $5.1(34)$ & \\
\hline \multicolumn{5}{|l|}{ Handgun in household } \\
\hline Yes & & 290 & $19.3(56)$ & \multirow[t]{2}{*}{0.001} \\
\hline No, only long gun & & 383 & $4.2(16)$ & \\
\hline \multicolumn{5}{|l|}{ CAGE score of 2 or more } \\
\hline Yes & 177 & 124 & $13.0(23)$ & \multirow[t]{2}{*}{0.004} \\
\hline No & 799 & 587 & $6.6(53)$ & \\
\hline \multicolumn{5}{|c|}{ Binge drinking in past 30 days } \\
\hline Yes & 235 & 194 & $9.4(22)$ & \multirow[t]{2}{*}{0.288} \\
\hline No & 746 & 520 & $7.2(54)$ & \\
\hline
\end{tabular}

${ }^{\star} \mathrm{p}$ Values were determined by the $\chi^{2}$ test of independence of the proportion with a loaded, unlocked firearm from the level of the household characteristic.

†This is an estimate adjusted for the residence region stratified sampling design. proportions of total study households with a firearm and with a firearm loaded and unlocked. We used PC SAS version 6.12 for all analyses.

\section{Results}

Of the 1004 households that participated in the study by the time enrollment stopped, 983 households had at least one adult who answered the questions about firearms. Nearly $67 \%$ (adjusted estimate based on 1990 census counts of households by residence type in study county) of households reported having firearms (table 1); $54 \%$ reported long guns (rifles and shotguns) only; $4 \%$ reported handguns only; and $36 \%$ had long guns and handguns (data not shown; type of firearm unknown for $6 \%$ ). The median number of guns of all types was three (range 1-150) per household (data not shown). The prevalence of firearms reported was $85.8 \%$ in farm households $v$ $61.1 \%\left(\chi^{2}\right.$ test, $\mathrm{p}=0.001$, based on test of equality of prevalence of firearms among three types of rural residence) in town households.

We found that $6.6 \%$ (adjusted estimate based on 1990 census counts of households by residence type in study county) of interviewed households had a loaded, unlocked gun in the home at the time of the survey (table 2). Coincidentally, the same percentage of households was reported to have all firearms stored most safely-locked, unloaded, and with the ammunition locked (data not shown). The prevalence of loaded guns in farm households, $10.5 \%$, was about twice the level in town households, $5.5 \%$ (table $2, \chi^{2}$ test, $\mathrm{p}=0.033$, based on test of equality of prevalence of loaded guns among three types of rural residence). More than 31\% of the 983 household respondents reported having taken a gun safety course. Having ever taken a gun safety course was associated with more than double the prevalence of a loaded gun in the household, $13.5 \%$ v $5.1 \%$ ( $\chi^{2}$ test, $\mathrm{p}=0.001)$. Of those trained, $22 \%$ said they received this training in the military (data not shown). Other commonly reported sources of training included the Izaak Walton League of America, high school, county sheriff, and hunting safety instructor. The prevalence of loaded guns in households with at least one handgun, $19.3 \%$, was four and one half times higher than in households with a long gun only, $4.2 \%\left(\chi^{2}\right.$ test, $\left.\mathrm{p}=0.001\right)$. Households with 
someone with a lifetime prevalence of alcohol abuse or dependence were about twice as likely as other households, $13.0 \% \vee 6.6 \%$ ( $\chi^{2}$ test, $\mathrm{p}=0.004)$, to report having loaded firearms.

Of all the correlations between pairs of exposure factors, only one exceeded 0.40 in absolute value. The younger the age group of the respondent, the more likely the household was to have minor children $(r=0.49$, $p=0.0001)$. Based on the weak correlations within pairs of exposure factors and the exploratory nature of this analysis, we did not conduct a multivariable reanalysis of the data.

\section{Discussion}

In a large population based, rural survey, households with handguns, alcohol abuse, or a history of a gun safety course were significantly more likely than were other households to have loaded, unlocked firearms.

Our finding of the existence of firearms in two thirds of study households is higher than reported elsewhere. Data from national telephone surveys indicate that $35 \%{ }^{4}$ or $38 \%{ }^{12}$ of households in the United States own guns. Telephone surveys conducted in 22 states (not including Iowa) in cooperation with the Centers for Disease Control and Prevention during 1991-95 reveal that household firearm prevalence ranges from $12 \%$ in New Jersey to $57 \%$ in Idaho. ${ }^{13}$ In Pennsylvania, home firearm presence is $59.9 \%$ in rural compared with $30.4 \%$ in urban counties. ${ }^{14}$

Of our study households with firearms, $10.6 \%$ had a loaded, unlocked gun at home at the time of the survey compared with $20 \%{ }^{4}$ and $21 \%{ }^{15}$ in recent national surveys of gun owners. Among the 22 states with information, the prevalence of loaded firearms varies from $1 \%$ of households in Rhode Island to $23 \%$ of households in Louisiana and Mississippi. ${ }^{13}$ As in other studies, ${ }^{13-19}$ our survey finds that when children are present in the household, the likelihood of loaded, unlocked firearms drops substantially. Beginning in 1989, several states, including Iowa, passed laws that make gun owners criminally liable if someone is injured because a child gains unsupervised access to a gun. ${ }^{20}$ Also as in other investigations, ${ }^{41517}$ our research reveals a strong association between handguns and loaded, unlocked guns in households. This could be because handguns are more often acquired for self defense, and their owners want a weapon to be available quickly if necessary. Our results on firearm safety training and storage practices concur with some reports and conflict with others. We found that households with a respondent who had taken a past gun safety course were about twice as likely as other households to have a loaded, unlocked gun, as did Hemenway et al in a 1994 survey of gun owners in the United States. ${ }^{15}$ In two other national surveys, ${ }^{4}{ }^{17}$ the proportion of gun owners who stored a gun loaded, unlocked did not differ according to the owner's history of firearm training.

We are concerned about those households with a coexistence of two hazards, including loaded, unlocked firearms and alcohol abuse or

\section{Key points}

- A stratified random sample of 983 rural Iowa households were interviewed.

- Nearly $67 \%$ of households reported having firearms.

- Nearly $7 \%$ of households reported having a loaded, unlocked gun.

- Homes with handguns, history of gun safety training, or alcohol abuse were more likely to have loaded, unlocked firearms.

- Reducing the proportion of rural homes with unsafely stored firearms may require consideration of these observations.

dependence. Ours is one of the few studies we know of that assesses unsafe firearm and alcohol behaviors in the same population. We are unaware of any other study that assesses the relationship between CAGE results and firearm storage practices. In this field, different study samples and definitions probably contribute to variations in findings. Diener and Kerber, who reported that $19 \%$ of gun owners compared with $9 \%$ of non-gun owners became drunk several times a month or more, first identified the problem of guns and alcohol. ${ }^{21}$ In addition, Williams and Singh found that $24.5 \%$ of alcohol abusers, $16.9 \%$ of other drinkers, and $13.2 \%$ of abstainers had ever been threatened with a gun or shot at. ${ }^{22}$ Intoxication has been recognized as a risk factor for motor vehicle crash injury, but Rutledge and Messick found this condition to be nearly as high in persons who died of gunshot wounds $(31.1 \%)$ as in persons who died of motor vehicle crashes $(35.7 \%) .^{23}$ Goldberg et al reported that $24.2 \%$ of those who drank at least six alcoholic beverages at least once a month compared with only $12.3 \%$ of those who drink less or none had a loaded gun in their home. ${ }^{24}$ In a study of gun owners, Hemenway and Richardson found the risk of owning an automatic or semiautomatic gun to be about twofold higher among respondents who had more than five drinks in one sitting in the past 60 days than among other respondents. ${ }^{25}$ Similarly, Nelson et al reported the prevalence of a firearm in the household being always or sometimes loaded and unlocked to be about twofold higher if the respondent drank five or more drinks one or more times in the past month. ${ }^{16}$

This study has several strengths. It examines in detail three different residential strata of rural society. It uses questions that ask directly and clearly about current firearm practices. Participants had no obvious reasons for distorting reports of firearm prevalence, alcohol use, or other variables. The level of binge drinking in our study is very similar to the level estimated in 1995 in Iowa by the Centers for Disease Control and Prevention Behavioral Risk Factor Surveillance System. ${ }^{26}$ Although the response rate of $42.1 \%$ was lower than expected, the social characteristics of participating and refusing households were similar. Finally, the weak correlations between the study exposure factors make it unlikely that the 
findings in our report can be explained by confounding.

There are some study limitations. Two published works provide reassuring evidence that valid data can be obtained from firearm self reports, although only firearm presence, not storage practices, was assessed. ${ }^{27}$ Social acceptability bias is a possibility for our study outcome and exposure factors. Individuals are more likely to give socially desirable answers in face-to-face interviews than in telephone interviews. ${ }^{29}$ Our survey did not ask the reason that households have firearms, so we cannot assess whether owning a firearm for self protection is associated with type of firearm storage. We did not ask about other factors that may be related to storage behavior, such as gun safety course time, duration, content, or instructor, or participants' knowledge or beliefs about safe gun storage.

\section{Implications for prevention}

In rural Iowa, two thirds of homes have firearms, and homes where handguns are kept or alcohol is abused are more likely to have loaded and unlocked guns than are other homes. Anyone interested in promoting safe storage of rural home firearms should consider these observations when selecting target populations or designing clinical or community interventions.

\section{This study was conducted with funds from the National
Institute for Occupational Safety and Health (U07 CCU 706145-05-1) and the National Center for Injury Prevention and Control (R49 CCR 703640-08), US Centers for Disease and Control (R49 CCR \\ We thank Jeffrey J Sacks, MD, MPH of CDC for sharing the Injury Control and Risk Survey (ICARIS) questionnaire. We thank Diana Jackson for interviewing the majority of study par- ticipants. We also thank Ann Stromquist, PhD, Jill Moore, Beth Henning, Ann Yeoman, and Naomi Tucker for conducting additional interviews. We thank Kevin M Kelly, $\mathrm{PhD}$, for assist- ance with data analysis, interpretation of analyses, and reviewing the draft manuscript.}

1 Bonnie RJ, Fulco CE, Liverman CT. Reducing the burden of injury: advancing prevention and treatment. Washington, DC: National Academy Press, 1999: 124

2 Fingerhut LA, Warner M. Injury chartbook. Health, United States, 1996-97. Hyattsville, MD: National Center fo Health Statistics, 1997: 59-60.

3 Karlson TA, Hargarten SW. Reducing firearm injury and death: a public health sourcebook on guns. New Brunswick, NJ: Rutgers University Press, 1997: figure 1.1.

4 Cook PJ, Ludwig J. Guns in America: national survey on private ownership and use of firearms. Washington, DC: US Department of Justice, National Institute of Justice, 1997.
5 Howard KA, Webster DW, Vernick IS. Beliefs about the risks of guns in the home: analysis of a national survey. Inj Prev 1999;5:284-9.

6 Mercy JA, Houk VN. Firearm injuries: a call for science. $N$ Engl f Med 1988;319:1283-4.

7 Baker SP, O'Neill B, Ginsburg MJ, et al. The injury fact book. 2nd Ed. New York, NY: Oxford University Press, 1992: $152-4$.

8 Stromquist AM, Merchant JA, Burmeister LF, et al. The Keokuk County rural health study: methodology and demographics. Fournal of Agromedicine 1997;4:243-8.

9 Ewing JA. Detecting alcoholism. The CAGE questionnaire. fAMA 1984;252:1905-7.

10 Buchsbaum DG, Buchanan RG, Centor RM, et al. Screening for alcohol abuse using CAGE scores and likelihood ratios. Ann Intern Med 1991;115:774-7.

11 Smith PF, Remington PL, Williamson DF, et al. A comparison of alcohol sales data with survey data on self-reported alcohol use in 21 states. Am f Public Health 1990;80:30912.

12 Smith TW. 1998 National gun policy survey of the National Opinion Research Center: Research findings. Chicago: University of Chicago, National Opinion Research Center, 1999: 10 .

13 Powell KE, Jacklin BC, Nelson DE, et al. State estimates of household exposure to firearms, loaded firearms, and handguns, 1991 through 1995. Am f Public Health 1998;88:969-72.

14 Forjuoh SN, Coben JH, Dearwater SR. Firearm ownership and storage practices in Pennsylvania homes. Inj Prev 1996;2:278-82.

15 Hemenway D, Solnick SJ, Azrael DR. Firearm training and torage. $\mathcal{F} A M A$ 1995;273:46-50.

16 Nelson DE, Grant-Worley JA, Powell K, et al. Population estimates of household firearm storage practices and firearm carrying in Oregon. $\mathcal{F} A M A$ 1996;275:1744-8.

17 Weil DS, Hemenway D. Loaded guns in the home. Analysis of a national random survey of gun owners. $F A M A$ 1992;267:3033-7.

18 Schuster MA, Franke TM, Bastian AM, et al. Firearm storage patterns in US homes with children. Am $\mathcal{f}$ Public Health 2000;90:588-94.

19 Stennies G, Ikeda R, Leadbetter S, et al. Firearm storage practices and children in the home, United States, 1994. Arch Pediatr Adolesc Med 1999;153:586-90.

20 Cummings P, Grossman DC, Rivara FP, et al. State gun safe storage laws and child mortality due to firearms. $7 A M A$ 1997;278:1084-6.

21 Diener E, Kerber KW. Personality characteristics of American gun-owners. F Soc Psychol 1979;107:227-38.

22 Williams JS, Singh BK. Alcohol use and antisocial experiences. Adv Alcohol Subst Abuse 1986;6:65-75.

23 Rutledge R, Messick WJ. The association of trauma death and alcohol use in a rural state. F Trauma 1992;33:737-42.

24 Goldberg BW, Whitlock E, Greenlick M. Firearm ownership and health care workers. Public Health Rep 1996;111: 256-9.

25 Hemenway D, Richardson E. Characteristics of automatic or semiautomatic firearm ownership in the United States. Am f Public Health 1997;87:286-8.

26 Powell-Griner E, Anderson JE, Murphy W. State-and sex-specific prevalence of selected characteristicsbehavioral risk factor surveillance system, 1994 and 1995. Morb Mortal Wkly Rep CDC Surveill Summ 1997;46:1-31.

27 Rafferty AP, Thrush JC, Smith PK, et al. Validity of a household gun question in a telephone survey. Public Health Rep 1995;110:282-8.

28 Kellermann AL, Rivara FP, Banton J, et al. Validating survey responses to questions about gun ownership among owners of registered handguns. Am f Epidemiol 1990;131:1080-4.

29 Armstrong BK, White E, Saracci R. Principles of exposure measurement in epidemiology. New York, NY: Oxford University Press, 1992: 37-9. 